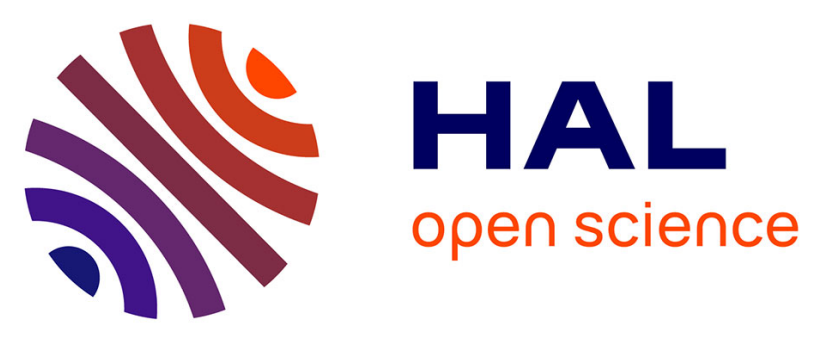

\title{
355 nm-laser pumped hydrogen UV Raman comb
}

Matthieu Chafer, Benoît Beaudou, Jonas Osorio, Frédéric Delahaye, Foued

Amrani, Benoît Debord, Frédéric Gérôme, Fetah Benabid

\section{To cite this version:}

Matthieu Chafer, Benoît Beaudou, Jonas Osorio, Frédéric Delahaye, Foued Amrani, et al.. 355 nm-laser pumped hydrogen UV Raman comb. Conference on Laser and Electro-Optics /Europe (CLEO/Europe-EQEC 2019), Jun 2019, Munich, Germany. Paper CJ-3.5. hal-02329738

\section{HAL Id: hal-02329738 \\ https://hal.science/hal-02329738}

Submitted on 23 Nov 2020

HAL is a multi-disciplinary open access archive for the deposit and dissemination of scientific research documents, whether they are published or not. The documents may come from teaching and research institutions in France or abroad, or from public or private research centers.
L'archive ouverte pluridisciplinaire HAL, est destinée au dépôt et à la diffusion de documents scientifiques de niveau recherche, publiés ou non, émanant des établissements d'enseignement et de recherche français ou étrangers, des laboratoires publics ou privés. 


\section{5 nm-laser pumped hydrogen UV Raman comb}

\section{Matthieu Chafer ${ }^{1}$, Benoit Beaudou', Jonas H. Osório ${ }^{2}$, Frédéric Delahaye ${ }^{2}$, Foued Amrani², Benoit Debord $^{1,2}$, Frédéric Gérôme ${ }^{1,2}$ and Fetah Benabid ${ }^{* 1,2}$}

1. GLOphotonics SAS, 123 avenue Albert Thomas 87060 Limoges Cedex

2. GPPMM group, Xlim Research Institute, CNRS UMR 7252, Université de Limoges, F-87000 Limoges, France

Ultraviolet (UV) laser sources are of great interest in a large number of applications such as spectroscopy, bio-medicine, gas detection, water and food decontamination to cite a few. Unfortunately, the covering of this range of wavelengths is tedious due to the lack of gain media that combine, compactness, high power levels and emission at wavelengths lower than $300 \mathrm{~nm}$. Hitherto, the existing UV laser sources are usually cumbersome, short-lived and cover a limited number of wavelengths.

Here we propose a multiple wavelength Raman-comb source based on a frequency-tripled micro-chip laser pumped hydrogen-filled hollow-core photonic crystal fiber (HCPCF) to overcome these shortcomings. Whilst, broad Raman spectra have been already been demonstrated, however, the generated Raman combs were limited in spectral components or optical spectral density in the UV [1].

Figure 1 the measured output spectrum of this HCPCF based Raman source, and which exhibits no less than 20 Raman lines in the range $250 \mathrm{~nm}$ to $400 \mathrm{~nm}$.

The result was achieved using a UV low transmission loss inhibited coupling (IC) HCPCF. The fiber shows a tubular design cladding composed of 8 tubes and a core diameter of $27 \mu \mathrm{m}$. It exhibits optical overlap between the cladding mode and the core mode of only $\sim 10^{-6}$, thus enabling in principle to solve the problem of solarization effect [2]. The measured transmission were found to be beneath a $100 \mathrm{~dB} / \mathrm{km}$ level in the UV with transmission observed down to $230 \mathrm{~nm}$. This leads to the possibility of generating a Raman comb in the UV by directly pumping a HCPCF with a microchip laser at $355 \mathrm{~nm}$. The fiber has then been filled with hydrogen gas with a pressure that can be monitored and sealed in order to generate a Raman comb optimized for the UV. The energy of the laser pump was set at the maximum of $15 \mu \mathrm{J}$ and coupled in this system with an efficiency superior to $85 \%$. A systematic study has been performed by playing on the fiber length and on the pressure of the hydrogen in order to optimize the UV components of the spectrum. The optimum fiber length is found to be 120 $\mathrm{cm}$ with a hydrogen pressure of 2 bars. The resulted Raman comb covers 4 lines in the UV-C, 8 lines in the UV$\mathrm{B}$ and 9 lines in the UV-A if we include the pump. The total energy was measured to be $12.5 \mu \mathrm{J}$ with high spectral densities, ranging from $4 \mu \mathrm{W} / \mathrm{nm}$ at $269 \mathrm{~nm}$ to $4 \mathrm{~mW} / \mathrm{nm}$ at $362 \mathrm{~nm}$.
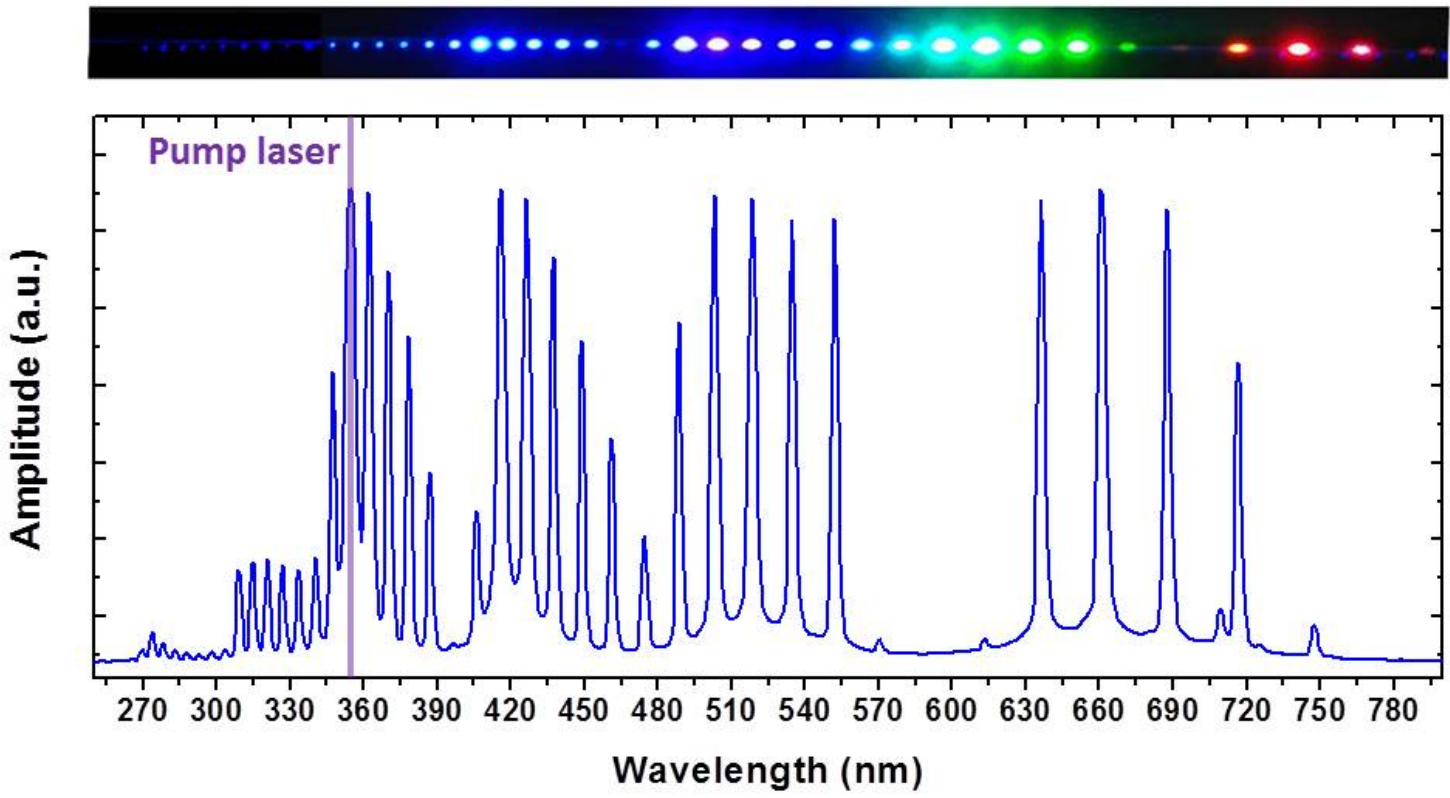

Fig. 1 Picture and spectrum of the Raman comb generated in $120 \mathrm{~cm}$ fiber filled in with 2 bars of hydrogen pumped by a microchip laser at $355 \mathrm{~nm}$.

The authors acknowledge support from PIA 4F, DGA and la région Nouvelle Aquitaine.

\section{References:}

[1] P. Hosseini, A. Abdolvand, and P. St.J. Russell, "Two-Octave-Wide UV-VIS Raman Spectra Generated in Hollow-Core PCF filled with gas mixtures", Conference on Lasers and Electro-Optics, 2016.

[2] M. Chafer, F. Delahaye, F. Amrani, B. Debord, F. Gérôme, and F. Benabid, "1 km long HC-PCF with losses at the fundamental Rayleigh scattering limit in the green wavelength range," in Conference on Lasers and Electro-Optics, 2018, p. SF1K.3. 